\title{
Valproate Induced Hair Loss and Curly Hair in Bipolar Disorder
}

\author{
Ömer Faruk Uygur, Hilal Uygur \\ Department of Psychiatry, Necip Fazil City Hospital, Kahramanmaras, Turkey
}

\section{TO THE EDITOR}

Yasemin [1] reported that curly hair due to valproate in a patient with bipolar disorder for the first time. To the best of our knowledge, there is no bipolar disorder patient whose hair loss and curly hair due to valproate at the same time, in the literature. We aimed to present a case of hair loss and curly hair due to valproate at the same time in bipolar disorder and we want to contribute to the letter of Yasemin. Written informed consent for publication was obtained from the patient.

Valproate is one of the mood stabilizers commonly used in the treatment of bipolar affective disorders. Well known side effects reported on valproate administration are tremor, weight gain, gastrointestinal disorders, liver dysfunction, metabolic acidosis, and thrombocytopenia. In addition, cosmetic side effects such as hair loss, color changes, thinning and curling of hair have also been reported in valproate-treated patients [2]. Alopecia or hair loss was found more frequently as a result of literature search with keywords "alproate" and "hair" on Google Search and PubMed for articles related to the topic. On the other hand, curly hair is a very rare side effect of valproate [3]. A study on a group who used valproate indicated that 5 out of 295 patients who were using valproate experienced curling of hair [4].

The patient is 50 years old and has had a diagnosis of bipolar disorder for 26 years. She has experienced four manic and three depressive episodes. She had used valproate or valproate plus quetiapin or valproate plus olan-

Received: May 2, 2019 / Accepted: June 18, 2019

Address for correspondence: Ömer Faruk Uygur

Department of Psychiatry, Kahramanmaras Necip Fazıl City

Hospital, Gaziantep road 12. Km 46050 Dulkadiroglu,

Kahramanmaras, Turkey

E-mail: drofuygur@hotmail.com

ORCID: https://orcid.org/0000-0003-2376-5113 zapine at different periods until the last two years. She discontinued her treatment in 2017 for a period of two years, resulting in hypomanic episode. We started valproate and titrated 1,250 mg/day. She noticed that her hair lossed and then it was curly growed at the ninth month of valproate usage. There were no other medical illness or drugs that could explain this condition. She has never had any perming of the hair performed. Her hair has remained curly during follow up the patient.

The mechanism of valproate effects on hair is not completely clear. Hair loss with valproate is dose-dependent and there is a decrease in biotinidase activity during valproate treatment and can be prevented by applying biotin to experimental rats [5]. It is the other most frequently proposed hypothesis that the inhibitory effect of the metals chelating and metal enzymes can lead to this [3]. Surprisingly, despite oral valproate administration that cause hair loss, hair regeneration was detected in experiments with topical valproate [6]. Hair loss and curly hair is not well known side effect of valproate. Psychiatrists should recognize the cosmetic side effects of valproate on hair and informed to patient.

\section{Conflicts of Interest}

No potential conflict of interest relevant to this article was reported.

\section{Author Contributions}

Funding: Ömer Faruk Uygur. Writing-review \& editing: Ömer Faruk Uygur. Supervision: Hilal Uygur.

\section{ORCID}

Ömer Faruk Uygur https://orcid.org/0000-0003-2376-5113 Hilal Uygur https://orcid.org/0000-0001-9438-8031

(c) This is an Open-Access article distributed under the terms of the Creative Commons Attribution Non-Commercial License (http://creativecommons.org/licenses/by-nc/4.0) which permits unrestricted non-commercial use, distribution, and reproduction in any medium, provided the original work is properly cited. 


\section{REFERENCES}

1. Yasemin G. Curly hair induced by valproate in bipolar disorder. Clin Psychopharmacol Neurosci 2016;14:114.

2. Kakunje A, Prabhu A, Sindhu Priya ES, Karkal R, Kumar P, Gupta N, et al. Valproate: it's effects on hair. Int J Trichology 2018:10:150-153.

3. Wilting I, van Laarhoven JH, de Koning-Verest IF, Egberts AC. Valproic acid-induced hair-texture changes in a white woman. Epilepsia 2007:48:400-401.

4. Ebrahimi H, Shamsadini S, Eshkavari SS. Frequency of sodium valproate-induced hair loss and curly hair. Iran I Pharmacol Ther 2005:4:143-145.

5. Tomita T, Goto H, Yoshida T, Tanaka K, Sumiya K, Kohda Y. Dose-dependent valproate-induced alopecia in patients with mental disorders. Indian J Pharmacol 2015;47:690-692.

6. Jo SJ, Shin H, Park YW, Paik SH, Park WS, Jeong YS, et al. Topical valproic acid increases the hair count in male patients with androgenetic alopecia: a randomized, comparative, clinical feasibility study using phototrichogram analysis. J Dermatol 2014;41:285-291. 